\title{
Additive Manufacturing towards the Fabrication of Greener Electrochemical Sensors for Antioxidants
}

\author{
Nélio I. G. Inoque, ${ }^{a, b}$ Lucas V. de Faria ${ }^{a}$ and Rodrigo A. A. Muñoz ${ }^{\circledR * a}$ \\ anstituto de Química, Universidade Federal de Uberlândia, 38400-902 Uberlândia-MG, Brazil \\ ${ }^{b}$ Escola Secundária de Sussundenga, Ministério da Educação e Desenvolvimento Humano, \\ Vila de Sussundenga, Provícia de Manica, Moçambique
}

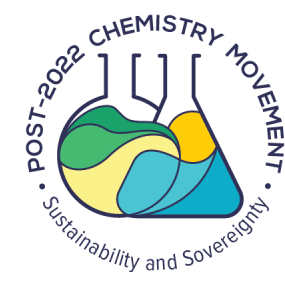

Additive manufacturing is an emerging tool that has contributed to the sustainable fabrication of devices in several areas based on the concept of "zero waste". Considering extrusionbased manufacturing (or 3D printing), polylactic acid (PLA) has been highlighted due to its biodegradability, obtention from renewable sources, and compatibility for 3D printing. Composites of PLA with conducting fillers, such as carbon-black (CB/PLA), are commercially-available and compatible with extrusion-based 3D printers and 3D pen. Herein, we investigate the electrochemical behavior of several antioxidant species (catechol, hydroquinone, propyl-gallate, octyl-gallate, dopamine, gallic acid and pyrogallol (PY)) on 3D-printed electrodes. Experiments by cyclic voltammetry demonstrated that electrochemical surface treatment in $\mathrm{NaOH}$ aqueous solution is an important strategy to improve the response of all antioxidants. Thus, PY was selected to evaluate the analytical performance of the proposed 3D-printed sensor. For this, a fast and simple method using batch-injection analysis with amperometric detection (BIA-AD) has been developed, which showed a limit of detection of $0.15 \mu \mathrm{mol} \mathrm{L}{ }^{-1}$, wide linear range $\left(0.5\right.$ to $\left.300 \mu \mathrm{mol} \mathrm{L}^{-1}\right)$, good precision (relative standard deviation $(\mathrm{RSD})<3.4 \%$ ) and selectivity. This method was applied in biodiesel samples, after dilution (400-fold) in electrolyte. Recovery percentages ranging from 82 to $119 \%$ attested absence of matrix effect and good accuracy.

Keywords: 3D printing, antioxidants, carbon black/polylactic acid, biodiesel, batch-injection analysis

\section{Introduction}

Additive manufacturing has been recognized as an emerging tool that enables cost-effective and efficient fabrication towards sustainability. Different areas have been benefited by additive manufacturing technologies, including aerospace, medicine, electronics, civil engineering, food and pharmaceutics. ${ }^{1}$ Additive manufacturing has also caused a great impact on chemistry, including organic synthesis in flow conditions, ${ }^{2}$ analytical chemistry from separation to detectors ${ }^{3-5}$ catalysis ${ }^{6}$ and electrochemistry (energy and sensing applications)..$^{7-9}$

There are different types of additive manufacturing techniques, also named as three-dimensional printing (3D printing) and some of them has been applied for electrochemical applications, such as ink-jet printing, extrusion-based of polymeric filaments and

*e-mail: munoz@ufu.br

Editor handled this article: Teodoro S. Kaufman photopolymerization under ultraviolet light. ${ }^{10}$ The most affordable and employed technique for the construction of electrochemical devices is based on the deposition of extruded filaments, also named as fused deposition modelling (FDM), which was enabled by the obtaining of conductive filaments. ${ }^{11}$ Polylactic acid (PLA) filaments containing graphene, carbon-black or nanocarbon conductive particles have been applied to produce electrochemical sensors. ${ }^{12-14}$ PLA is a biopolymer, that is obtained from renewable sources and biodegradable, thus offers great promises to the 3D printing sustainable electrochemical devices. ${ }^{15}$ Carbon electrochemistry has been well documented in the literature, hence the comparison of the electrochemical activity of the 3D-printed electrodes with conventional ones, such as glassy-carbon electrode, boron-doped diamond electrode, carbon-paste electrode or screen-printed electrode, is easily assessed. ${ }^{16,17}$ The performance of 3D-printed electrodes using PLA containing graphene or carbon black is poor when compared with such conventional electrodes, however, after a surface treatment, it can be 
dramatically improved..$^{18}$ One simple protocol to improve the electrochemical activity of 3D-printed carbon electrodes is the electrochemical treatment in a $\mathrm{NaOH}$ solution, which consumes the PLA matrix and makes more available the conductive particles within the polymeric matrix. ${ }^{17,19}$

Desktop FDM 3D printers are widely available worldwide, they can be constructed following tutorials using low-cost parts that can also be 3D printed, which certainly contributed to their great popularity. ${ }^{20}$ Analogous to such 3D printers, 3D pen that is available as a toy for kids can also be employed to fabricate electrochemical sensors. ${ }^{21}$ Advantages include the reduced amount of filament required to prototype a device, hand-held portability, and much lower cost. The obvious disadvantage is the absence of the precise threedimensional control of the 3D-printer extruder. The solution found by different groups to overcome this drawback is the use of customized templates. ${ }^{22,23}$

In this context, we show a novel application of 3D-printed electrodes using PLA containing conductive carbon-black particles, which after electrochemical treatment provides excellent electrochemical activity to the oxidation of diverse antioxidants. We also show how 3D-printed electrodes can be applied for the detection of the antioxidant pyrogallol in biodiesel, a complex sample, with great analytical features, including wide linear range, low limit of detection and high sample throughput using batch injection analysis with amperometric detection (BIA-AD). This technique has been reported by different groups worldwide due to its portability and simplicity of operation, important features for routines analyses. ${ }^{24-27}$ The proposed BIA-AD method using 3D-printed electrodes presents superior sensing performance in comparison with other electroanalytical methods previously reported.

\section{Experimental}

Instrumentation, electrochemical cell and electrodes

All electrochemical recordings were performed using an $\mu$-AUTOLAB Type III potentiostat/galvanostat (Metrohm Autolab BV, Utrecht, the Netherlands) coupled to a computer. The NOVA 2.1.4 software for windows 10 was used to control the instrument. Data were treated using the OriginPro8.5 software ${ }^{28}$ for graphing and analysis (Northampton, MA, USA). The cyclic voltammetric (CV) measurements were performed using a $10 \mathrm{~mL}$ beaker and amperometric experiments were carried out using a 3D-printed BIA electrochemical cell (internal volume of $100 \mathrm{~mL}$ ), as prototyped by Cardoso et al..$^{16} \mathrm{In}$ this analysis system, all injections were conducted using an Eppendorf electronic micropipette (Multipette ${ }^{\circledR}$ E3, Hamburg,
Germany), which permits injections from $1 \mu \mathrm{L}$ to $1 \mathrm{~mL}$ (using a $1 \mathrm{~mL}$ Combtip $^{\circledast}$, Hamburg, Germany) at a programmable dispensing rate (from 17 to $300 \mu \mathrm{L} \mathrm{s}^{-1}$ ). The reference and auxiliary electrodes were an $\mathrm{Ag} \mid \mathrm{AgCl}$ (saturated $\mathrm{KCl}$ ) and a platinum wire, respectively. As working electrode, two different prototypes were proposed (tubular and planar), both composed of conductive carbon black/polylactic acid (CB/ PLA) thermoplastic filament (Proto-Pasta ${ }^{\circledR}$ ) obtained from Proto Plant Inc. (Vancouver, Canada).

\section{Reagents and solutions}

All solutions were prepared with high-purity deionized water (resistivity $\geq 18 \mathrm{M} \Omega \mathrm{cm}$ ) obtained from a Direct-Q3 water purification system (Millipore, Bedford, MA, USA). Concentrated perchloric acid $(70 \% \mathrm{~m} / \mathrm{v})$, acetic acid $(99.7 \% \mathrm{~m} / \mathrm{v})$ from Vetec (Rio de Janeiro, Brazil), ethanol $(99.8 \% \mathrm{v} / \mathrm{v})$, sodium hydroxide $(98 \% \mathrm{~m} / \mathrm{m})$ and phosphoric acid $(85 \% \mathrm{~m} / \mathrm{v})$ from Synth (São Paulo, Brazil) and boric acid (99.9\%) from Acros Organics (USA) were diluted in an appropriate concentration to study the composition of the supporting electrolyte. The following antioxidants were evaluated: catechol (CT) $(99 \% \mathrm{~m} / \mathrm{m})$ from Acros Organics (New Jersey, USA), hydroquinone (HQ) $(99 \% \mathrm{~m} / \mathrm{m})$ from Vetec (Rio de Janeiro, Brazil), octyl gallate (OG) $(\geq 99 \% \mathrm{~m} / \mathrm{m})$, dopamine hydrochloride (DP), gallic acid (GA) $(\geq 97.5 \% \mathrm{~m} / \mathrm{m})$, propyl gallate $(\mathrm{PG})(\geq 98 \% \mathrm{~m} / \mathrm{m})$, and pyrogallol (PY) $(\geq 98 \% \mathrm{~m} / \mathrm{m})$ from Sigma-Aldrich (St. Louis, USA). The standard stock solutions of PY, PG, OG and GA were prepared in ethanol (99.8\% v/v) and CT, HQ and DP were prepared in deionized water. Aqueous standard solutions of $\mathrm{Cu}^{\mathrm{II}}, \mathrm{Fe}^{\mathrm{III}}, \mathrm{Pb}^{\mathrm{II}}, \mathrm{Mn}^{\mathrm{II}}, \mathrm{Zn}^{\mathrm{II}}$ and $\mathrm{Cd}^{\mathrm{II}}$ (all at $1000 \mathrm{mg} \mathrm{L}^{-1}$ ) were purchased from Quimlab (Jacareí, Brazil). The Britton-Robinson (BR) buffer solution $\left(0.12 \mathrm{~mol} \mathrm{~L}^{-1}\right)$ was prepared using equimolar mixture of acetic, boric, and phosphoric acids. The adjustment of $\mathrm{pH}$ values was carried out using a $1.0 \mathrm{~mol} \mathrm{~L}^{-1} \mathrm{NaOH}$ solution.

Two methyl biodiesel samples were analyzed, one produced from soybean oil in the laboratory according to a procedure described in the literature ${ }^{29}$ and another sample donated by a biodiesel power plant (Caramuru, Itumbiara, Brazil) identified as commercial biodiesel. These biofuels samples were free from synthetic antioxidants according to previous analyses.

\section{Production of 3D-printed CB/PLA electrodes}

Twenty-five customized cylinders $(3.5 \mathrm{~cm}$ length $\times$ $3.8 \mathrm{~mm}$ diameter) were 3D-printed in an Anycubic Photon digital UV light processing (DLP) from ANYCUBIC Co., Ltd. (Shenzen, China) using acrylic resin. Next, a 
3D pen from Sanmersen (Shenzhen, China) was used to print the conductive part of each electrode using a $\mathrm{CB} /$ PLA conductive filament. This step is made one-by-one manually and takes around 1 min each electrode. The pen has a speed controller and an integrated heating nozzle from which the molten filament is released. The fabrication of planar CB/PLA electrodes using FDM 3D-printer from Dreamer NX, Flash Force (Zheijang, China) was based on previous work. ${ }^{16}$ Briefly, four rectangles (40 mm length $\times 15 \mathrm{~mm}$ width $\times 1.8 \mathrm{~mm}$ height) were 3D-printed employing the conductive CB/PLA filament. The layer height was set at $0.25 \mathrm{~mm}$, with 2 shells (outer perimeter toolpaths) and $100 \%$ infill density.

After fabrication, both 3D-printed CB/PLA working electrode were polished in a sandpaper (600 grit followed by 1200 grit) moistened with ultrapure water until a homogeneous surface was obtained. Next, an electrochemical treatment procedure of the 3D-printed $\mathrm{CB} / \mathrm{PLA}$ electrodes was performed by amperometry in $\mathrm{NaOH}\left(0.5 \mathrm{~mol} \mathrm{~L}^{-1}\right)$ solution, with application of a potential of $+1.4 \mathrm{~V}$ per $200 \mathrm{~s}$, followed by a potential of $-1.0 \mathrm{~V}$ for the same time. This protocol was optimized in a previous work that showed the great exposure of carbon black conducting sites. ${ }^{19}$

\section{Electrochemical measurements}

The electrochemical measures were executed without removing dissolved oxygen and at laboratory room temperature (around $25{ }^{\circ} \mathrm{C}$ ). The polishing process and electrochemical activation employing $0.5 \mathrm{~mol} \mathrm{~L}^{-1} \mathrm{NaOH}$ were sequentially performed at the beginning of each working day as described in the "Production of 3D-printed CB/PLA electrodes" sub-section.

The electrochemical behavior of different antioxidant species was performed by $\mathrm{CV}$ on untreated and treated surfaces. The $\mathrm{pH}$ effect on the electrochemical response of PY $\left(1 \mathrm{mmol} \mathrm{L}^{-1}\right)$ was evaluated using BR buffer solution $\left(0.12 \mathrm{~mol} \mathrm{~L}^{-1}\right)$ with $\mathrm{pH}$ values ranging from 2.0 to 8.0 (Figure S1, Supplementary Information (SI) section). For the determination of PY in biodiesel by BIA-AD, the parameters, working potential, dispensing rate and injection volume were optimized using a PY standard solution $(100 \mu \mathrm{mol} \mathrm{L}-1)$ with measurements in triplicates $(n=3)$.

\section{Biodiesel sample preparation}

Biodiesel samples were initially diluted 40 -fold in ethanol, and then $1 \mathrm{~mL}$ aliquot of this solution was added to a $10 \mathrm{~mL}$ volumetric flask and the meniscus adjusted with BR buffer (0.12 $\left.\mathrm{mol} \mathrm{L}^{-1}, \mathrm{pH} 6.0\right)$.

\section{Results and Discussion}

\section{Electrochemical response of the antioxidants on the 3D-printed CB/PLA}

The electrochemical profiles of seven different antioxidants were investigated using the 3D-printed $\mathrm{CB} / \mathrm{PLA}$ electrodes. Figure 1 shows the voltammetric profile of PY, PG, OC, CT, HQ, DP and GA in $0.1 \mathrm{~mol} \mathrm{~L}^{-1} \mathrm{HClO}_{4}$ using untreated (red lines) and treated surfaces (blue lines).

The electrochemical oxidation of the seven antioxidants is feasible on the 3D-printed CB/PLA electrode with oxidation peaks at $+0.55 \mathrm{~V}$ for $\mathrm{CT},+0.59 \mathrm{~V}$ for $\mathrm{GA},+0.55 \mathrm{~V}$ for $\mathrm{DP}$, $+0.48 \mathrm{~V}$ for $\mathrm{HQ},+0.78 \mathrm{~V}$ for $\mathrm{OG},+0.62 \mathrm{~V}$ for $\mathrm{PG}$ and $+0.60 \mathrm{~V}$ for PY. Interestingly, all the electrochemical oxidation processes were facilitated on the electrochemically treated $\mathrm{CB} / \mathrm{PLA}$ electrode (blue lines) probably by the formation of oxygenated species and higher exposure of carbon black sites as documented in previous work. ${ }^{19}$ A previous work ${ }^{30}$ evaluated in details the surface changes of 3D-printed $\mathrm{CB} / \mathrm{PLA}$ electrodes after the same electrochemical protocol in $\mathrm{NaOH}$ solution using $\mathrm{X}$-ray spectroscopy and the authors revealed an increase in bonds $(\mathrm{C}-\mathrm{C})$ that indicated the formation of graphitic structures, probably due to the consumption of PLA exposing more carbon black sites after treatment. Such a surface modification contributed to the improved electrochemical oxidation of the antioxidants; however, further investigation is required to understand and prove this hypothesis.

Aiming at a sensitive and selective determination of $\mathrm{PY}$ in biodiesel samples, its electrochemical response was investigated at different $\mathrm{pH}$-values (2.0 to 8.0) using BR buffer, as shown in Figure S1 (SI section). A pH-dependent behavior was observed up to $\mathrm{pH}$ 8.0, after this value, $\mathrm{PY}$ shows low stability. From the linear adjustment between $\mathrm{E}_{\mathrm{P}}$ (peak potential) and $\mathrm{pH}$ (see Figure $\mathrm{S} 1 \mathrm{~B}$ ), slope values of 55 and $60 \mathrm{mV} \mathrm{pH}^{-1}$ were obtained, suggesting that the same number of protons and electrons are involved in both oxidation processes, which is in agreement with other works reported in the literature. ${ }^{31-33}$ Considering that $\mathrm{pH}$ 6.0 provided a better response as well as a considerable anticipation of both oxidation processes, this buffered solution was selected for further experiments.

\section{Determination of PY antioxidant in biodiesel by BIA-AD}

Initially, the BIA-AD parameters (working potential, dispensing rate and injected volume) were evaluated in order to provide good selectivity, increase in analytical response, lower consumption of reagents and higher analytical frequency. The influence of each parameter on 

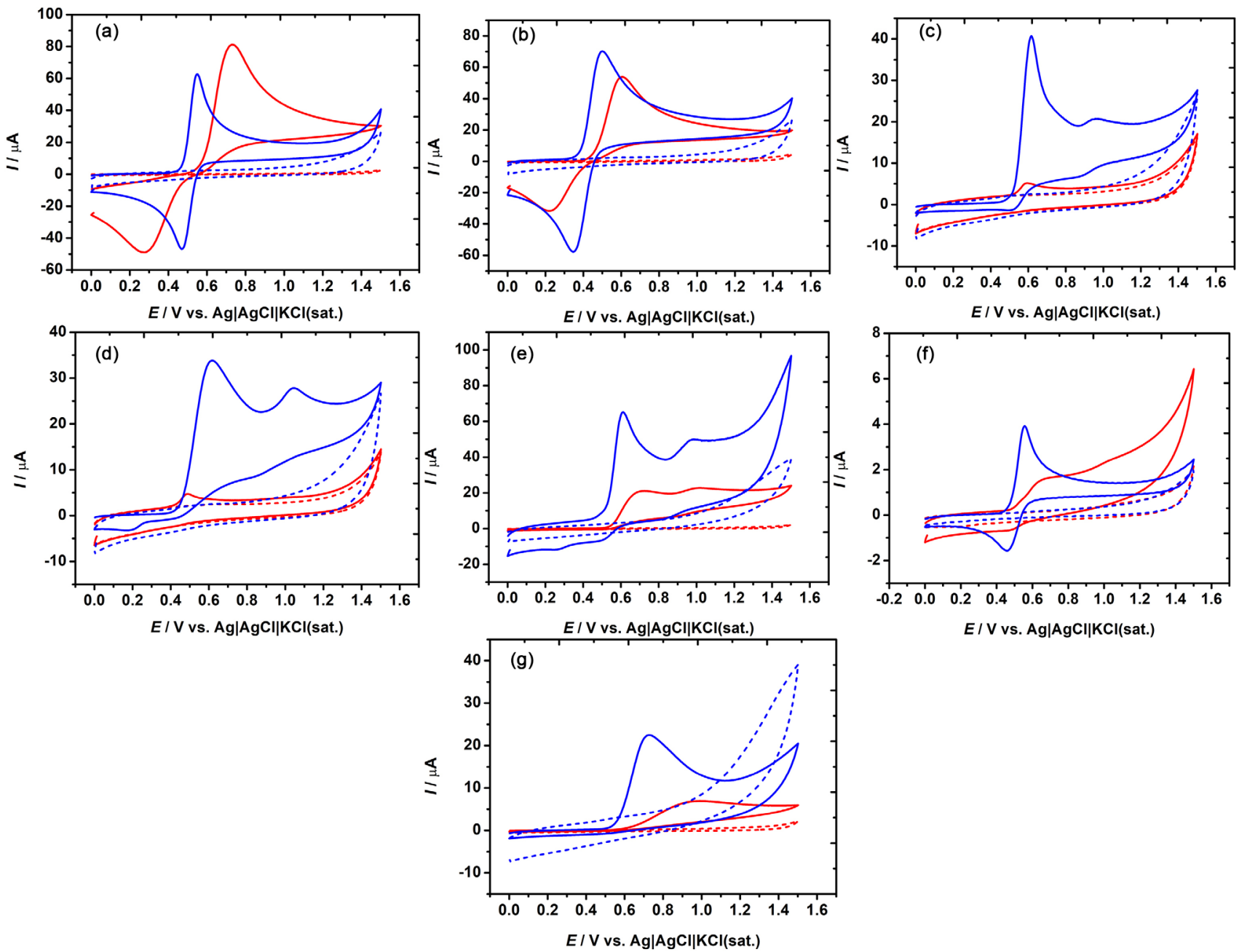

Figure 1. Cyclic voltammetric recordings for $1 \mathrm{mmol} \mathrm{L}^{-1}$ of each (a) CT, (b) $\mathrm{HQ}$, (c) PG, (d) PY, (e) GA, (f) DP, (g) OG in $0.1 \mathrm{~mol} \mathrm{~L}^{-1} \mathrm{HClO}_{4}$ in $10 \%$ (v/v) ethanol before (red line) and after (blue line) chemical/electrochemical treatment of electrode. The dashed lines correspond to the respective blanks. Other conditions: scan rate: $50 \mathrm{mV} \mathrm{s}^{-1}$ and step potential: $5 \mathrm{mV}$.

the electrochemical response of PY is shown in SI section (Figures S2, S3 and S4). Table 1 summarizes the assessed BIA-AD parameters, the studied range and the selected values for subsequent studies.

Table 1. Selection of the BIA-AD parameters for the determination of PY

\begin{tabular}{lcc}
\hline Parameter & $\begin{array}{c}\text { Studied } \\
\text { interval }\end{array}$ & $\begin{array}{c}\text { Selected } \\
\text { condition }\end{array}$ \\
\hline Working potential $v s . \mathrm{Ag} \mid \mathrm{AgCl}, \mathrm{KCl}_{\text {(sat.) }} / \mathrm{V}$ & $0.1-0.8$ & 0.4 \\
Dispensing rate / $\left(\mu \mathrm{L} \mathrm{s}^{-1}\right)$ & $17-300$ & 200 \\
Injected volume / $\mu \mathrm{L}$ & $50-300$ & 100 \\
\hline
\end{tabular}

BIA-AD: batch-injection analysis with amperometric detection; PY: pyrogallol.

Under the selected parameters listed in Table 1, the sensor was evaluated for the determination PY. The linear ranges between the peak currents and the concentration levels of PY were obtained from 0.5 to $300 \mu \mathrm{mol} \mathrm{L}^{-1}$ with good correlation coefficients, $r=0.996$ and $r=0.999$ for increasing and decreasing concentrations, respectively (Figure 2). Similar slopes, 0.2243 and 0.2124 , demonstrated the absence of memory effect after consecutive injections of PY standard solution. The linear regression equation, $\mathrm{I}_{\mathrm{pa}}(\mu \mathrm{A})=(0.224 \pm 0.006)[\mathrm{PY}](\mu \mathrm{M})-0.002 \pm 0.001$, was obtained for increasing concentration.

From these curves, the limit of detection (LOD) and quantification (LOQ) values for PY were estimated. LOD and LOQ values were calculated according to the International Union of Pure and Applied Chemistry $(\text { IUPAC })^{34}$ definition as follows: LOD $=3 \sigma / \mathrm{s}$ and $\mathrm{LOQ}=10 \sigma / \mathrm{s}$, in which $\sigma$ indicates the standard deviation of baseline noise while s corresponds to the sensitivity of the calibration curve (slopes).

Subsequently, a series of repetitive electrochemical determinations $(n=10)$ were performed to evaluate the precision of this method. The repeatability study was conducted with three different levels of concentration of PY 

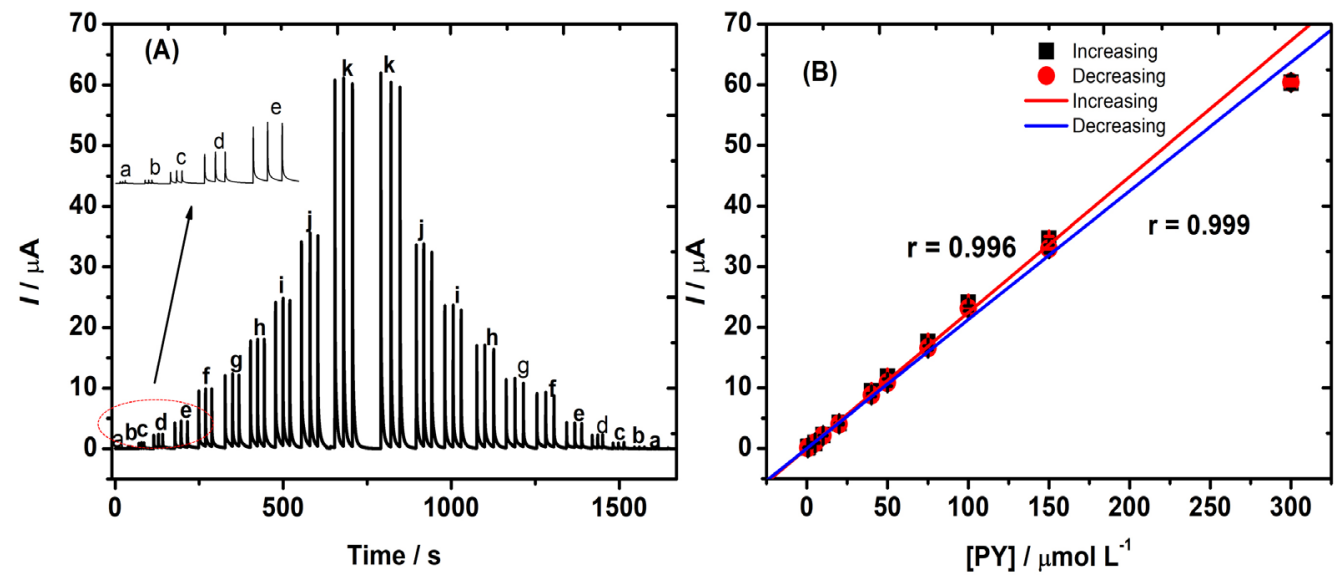

Figure 2. (A) BIA-AD responses for triplicate injections of (a) 0.5, (b) 1.0, (c) 5.0, (d) 10 (e) 20, (f) 40, (g) 50, (h) 75, (i) 100 (j) 150 and (k) $300 \mu \mathrm{mol} \mathrm{L}{ }^{-1}$ PY standard solutions in BR buffer $\left(0.12 \mathrm{~mol} \mathrm{~L}^{-1}, \mathrm{pH}\right.$ 6.0) and (B) respective calibration curves: increasing and decreasing PY concentrations. Optimized conditions in Table 1.
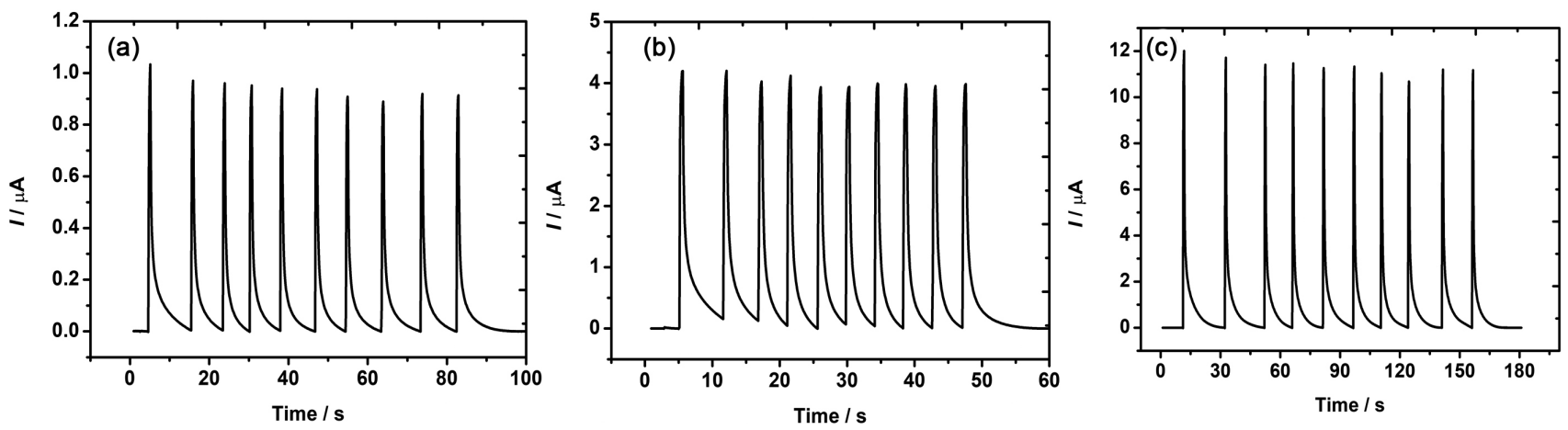

Figure 3. Repeatability data obtained from successive injections of a solution containing (a) 5 , (b) 20 and (c) $50 \mu m o l \mathrm{~L}^{-1} \mathrm{PY}$ ( $\left.\mathrm{n}=10\right)$. Analysis conditions: working potential: $+0.4 \mathrm{~V}$, dispensing rate: $200 \mu \mathrm{L} \mathrm{s}^{-1}$, injected volume: $100 \mu \mathrm{L}$, electrolyte: BR buffer $\left(0.12 \mathrm{~mol} \mathrm{~L}^{-1}\right.$, $\mathrm{pH} \mathrm{6.0)}$.

$\left(10,20\right.$ and $\left.50 \mu \mathrm{mol} \mathrm{L}^{-1}\right)$ (shown in Figure 3) using the same 3D-printed electrode. All relative standard deviation (RSD) values were lower than $3.36 \%$, indicating good precision.

The values of the inter-day variation were calculated by the RSD values of slopes from two analytical curves obtained in two different days. The electrode fabrication was evaluated by the inter-electrode variation and the values of $6.44 \%$ for PY proved the high reproducibility of the protocol. Table 2 describes the analytical features obtained for the PY using 3D-printed sensor associated with BIA-AD.

\section{Selectivity study}

The metallic ions, such as copper, iron, manganese and nickel, affect tremendously the biodiesel oxidative stability as the metallic species acts catalyzers of oxidation processes, leading to biodiesel degradation. ${ }^{35,36}$ Considering these negative effects, maximum limits for some contaminants, including water, methanol, sulfate, chloride, sodium, and iron, are established by regulatory agencies worldwide (e.g., in Europe, the US and Brazil). The Brazilian agency ANP presents a resolution ${ }^{37}$ that
Table 2. Analytical features of the BIA-AD method for PY determination

\begin{tabular}{lc}
\hline Analytical feature & Obtained value \\
\hline Linear range / $\left.(\mu \mathrm{mol} \mathrm{L})^{-1}\right)$ & $0.5-300$ \\
Sensitivity / $\left(\mu \mathrm{A} \mu \mathrm{mol} \mathrm{L}^{-1}\right)$ & $0.2243 \pm 0.006$ \\
Limit of detection / $\left(\mu \mathrm{mol} \mathrm{L}^{-1}\right)$ & 0.15 \\
Limit of quantification / $\left(\mu \mathrm{mol} \mathrm{L}{ }^{-1}\right)$ & 0.50 \\
Correlation coefficient & 0.996 \\
Analytical frequency / $\mathrm{h}^{-1}$ & 146.0 \\
Repeatability for $10 \mu \mathrm{mol} \mathrm{L}^{-1}$ and $\mathrm{n}=10 / \%$ & 3.36 \\
Repeatability for $20 \mu \mathrm{mol} \mathrm{L}^{-1}$ and $\mathrm{n}=10 / \%$ & 1.53 \\
Repeatability for $50 \mu \mathrm{mol} \mathrm{L}^{-1}$ and $\mathrm{n}=10 / \%$ & 3.21 \\
Inter-electrode for $100 \mu \mathrm{mol} \mathrm{L}^{-1}$ and $\mathrm{n}=3 / \%$ & 6.44 \\
Inter-day at the same electrode $(\mathrm{n}=2$ slopes) / \% & 4.43
\end{tabular}

BIA-AD: batch-injection analysis with amperometric detection; PY: pyrogallol.

defines a strict upper limit for some metallic ions $\left(\mathrm{Fe}^{\mathrm{III}}\right.$, $\mathrm{Cu}^{\mathrm{II}}, \mathrm{Pb}^{\mathrm{II}}, \mathrm{Mn}^{\mathrm{II}}$, and $\left.\mathrm{Cr}^{\mathrm{II}}\right)$ in the biofuel $\left(1.0 \mathrm{mg} \mathrm{kg}^{-1}\right)$. Such high amounts of metals in biodiesel may occur due to the corrosion of metallic parts (engines or tanks) in contact with the biofuel. ${ }^{38-40}$ 
The metallic species $\mathrm{Fe}^{\mathrm{III}}, \mathrm{Cu}^{\mathrm{II}}, \mathrm{Pb}^{\mathrm{II}}, \mathrm{Mn}^{\mathrm{II}}, \mathrm{Cd}^{\mathrm{II}}$ and $\mathrm{Zn}^{\mathrm{II}}$ were kept at $1 \mathrm{mg} \mathrm{L}^{-1}$ as interferents on the detection of

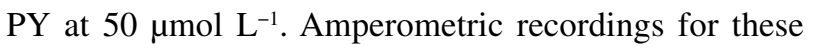
experiments are presented in Figure 4. Low deviations (lower than 7.13\%) were obtained for PY even after the addition of each interferent. All metallic species did not provide an electrochemical response concomitant with PY oxidation peaks, hence no interference from $\mathrm{Fe}^{\mathrm{III}}, \mathrm{Cu}^{\mathrm{II}}, \mathrm{Pb}^{\mathrm{II}}$, $\mathrm{Mn}^{\mathrm{II}}, \mathrm{Zn}^{\mathrm{II}}$ and $\mathrm{Cd}^{\mathrm{II}}$ was observed.

\section{Application in biodiesel samples}

After the analytical features were obtained, the BIA-AD method using the manufactured CB/PLA electrode was applied for the determination of PY in biodiesel samples (soybean and commercial).

The accuracy of the method was evaluated by additionrecovery tests, which means that the samples were spiked with known amounts of PY antioxidant in three levels, (2.5, 6.3 and $\left.12.6 \mathrm{mg} \mathrm{L}^{-1}\right)$ which correspond to 20,50 and

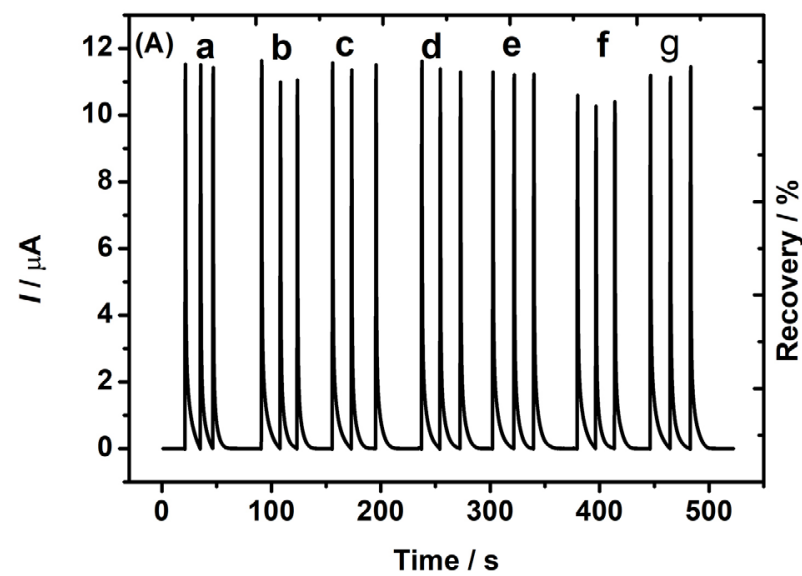

$100 \mu \mathrm{mol} \mathrm{L}{ }^{-1} \mathrm{PY}$ injected into the electrochemical cell. The content of antioxidant in biodiesel was estimated based on the literature to achieve $12 \mathrm{~h}$ of induction period by the Rancimat method, official protocol to measure oxidative stability. ${ }^{41}$

Figure 5 and Table 3 summarize the recovery values for the analysis of spiked biodiesel samples. Satisfactory recovery values were verified (from 82 to $119 \%$ ), according to the acceptance criteria for recovery, established by the National Institute of Metrology, Quality and Technology (INMETRO) $)^{42}$ of Brazil, showing acceptable accuracy in the level of studied concentrations and no interference problems from the sample matrix (soybean biodiesel and biodiesel plant samples) under the optimized conditions. Therefore, the acceptable recovery values indicated that the proposed BIAAD method can be used to quantify PY at low concentration levels using the 3D printed CB/PLA electrode.

The procedure developed for determination of $\mathrm{PY}$ in biodiesel using the $\mathrm{CB} / \mathrm{PLA}$ electrode was compared with

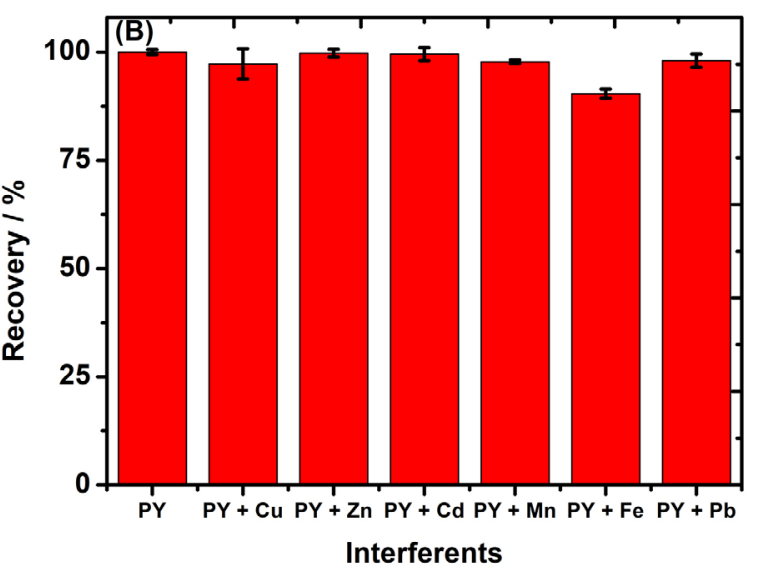

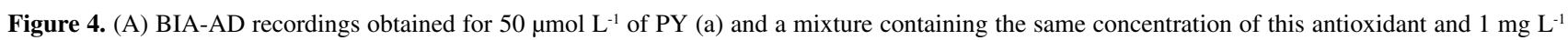
of (b) $\mathrm{Cu}^{\mathrm{II}}$, (c) $\mathrm{Zn}^{\mathrm{II}}$, (d) $\mathrm{Cd}^{\mathrm{II}}$, (e) $\mathrm{Mn}^{\mathrm{II}}$, (f) $\mathrm{Fe}^{\mathrm{III}}$ and (g) $\mathrm{Pb}^{\mathrm{II}}$ under the optimized conditions. (B) Interference percentage of each metal on the PY response.
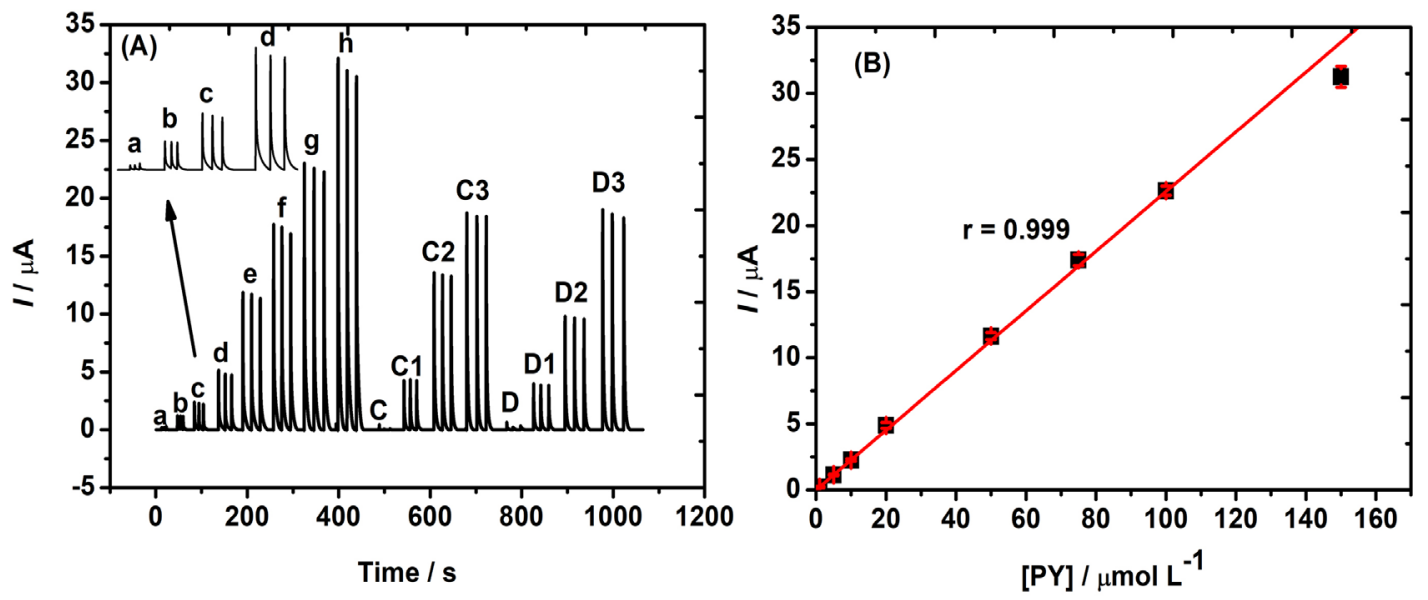

Figure 5. (A) Amperogram for PY determination by BIA-AD in soybean biodiesel (C), spiked soybean biodiesel (C1, C2 and C3), commercial biodiesel (D) and spiked commercial biodiesel (D1, D2 and D3). Analytical curve: (a) 1, (b) 5, (c) 10, (d) 20, (e) 50, (f) 75, (g) 100, and (h) 150 $\mu$ mol L-1. (B) Respective calibration curves. Analysis conditions: working potential: $+0.4 \mathrm{~V}$, dispensing rate: $200 \mu \mathrm{L} \mathrm{s}^{-1}$, injected volume: $100 \mu \mathrm{L}$, electrolyte: BR buffer $\left(0.12\right.$ mol $\mathrm{L}^{-1}$, $\mathrm{pH}$ 6.0). 
Table 3. Concentration and recovery values obtained for the analysis of biodiesel samples before and after spiking with PY $(n=3)$. Spiked values correspond to the concentration injected into the BIA-AD system after sample dilution

\begin{tabular}{|c|c|c|c|c|}
\hline Sample & Found / $\left(\mu \mathrm{mol} \mathrm{L}{ }^{-1}\right)$ & Spiked / $\left(\mu \mathrm{mol} \mathrm{L}{ }^{-1}\right)$ & Found $\pm \mathrm{SD} /\left(\mu \mathrm{mol} \mathrm{L}{ }^{-1}\right)$ & Recovery \pm SD / \% \\
\hline & $<$ LOD & 20 & $17.1 \pm 0.3$ & $86 \pm 2$ \\
\hline \multirow[t]{3}{*}{ Commercial biodiesel } & $<$ LOD & 50 & $42.8 \pm 0.6$ & $86 \pm 1$ \\
\hline & $<$ LOD & 100 & $83 \pm 2$ & $83 \pm 2$ \\
\hline & $<$ LOD & 20 & $18.8 \pm 0.2$ & $94 \pm 1$ \\
\hline \multirow[t]{2}{*}{ Soybean biodiesel } & $<$ LOD & 50 & $59.4 \pm 0.7$ & $119 \pm 1$ \\
\hline & $<$ LOD & 100 & $82.2 \pm 0.8$ & $82 \pm 1$ \\
\hline
\end{tabular}

BIA-AD: batch-injection analysis with amperometric detection; PY: pyrogallol; SD: standard deviation; LOD: limit of detection.

Table 4. Comparative methods: overview of the literature reported for the determination of PY in biodiesel by various electroanalytical techniques

\begin{tabular}{|c|c|c|c|c|c|}
\hline Technique & Electrode & $\mathrm{LOD} /\left(\mathrm{mg} \mathrm{L}^{-1}\right)$ & $\mathrm{LOQ} /\left(\mathrm{mg} \mathrm{L}^{-1}\right)$ & $\mathrm{RSD} / \%$ & Reference \\
\hline BIA-AD & CB/PLA & 0.019 & 0.063 & 3.36 & this work \\
\hline BIA-AD & MWCNT & 0.002 & n.m. & 3.0 & 43 \\
\hline LSV & MWCNT-SPE & 0.61 & 0.189 & 2.37 & 44 \\
\hline LSV & BDDE & 0.107 & 0.356 & 0.32 & 45 \\
\hline FIA-AD & SPE/PEDOT & 0.079 & 0.260 & 3.06 & 31 \\
\hline $\mathrm{CV}$ & GCE/CNT & 0.365 & 1.215 & n.m. & 46 \\
\hline $\mathrm{CV}$ & $\mathrm{SPCE} / \mathrm{CoPc}$ & 0.307 & 1.015 & n.m. & 47 \\
\hline
\end{tabular}

PY: pyrogallol; LOD: limit of detection; LOQ: limit of quantification; RSD: relative standard deviation; BIA-AD: batch-injection analysis with amperometric detection; LSV: linear sweep voltammetry; FIA-AD: flow injection analysis with amperometric detection; CV: cyclic voltammetry; MWCNT: multi-walled carbon nanotube; MWCNT-SPE: screen-printed electrode modified with multi-walled-carbon-nanotube; SPE/PEDOT: screen-printed electrode modified with poly(3,4-ethylenedioxythiophene); GCE/CNT: glassy carbon electrode modified wit carbon nanotubes; SPCE/CoPc: screen-printed carbon electrode modified with cobalt phthalocyanine; BDDE: boron-doped diamond electrode; CB/PLA: carbon black/polylactic acid electrode; n.m.: not mentioned.

other procedures available in the literature, as shown in Table 4.

The evaluated parameters, including type of working electrode, limit of detection (LOD), limit of quantification (LOQ) and precision, denote that the proposed method provides equivalent or better results to those already existing in the literature. Furthermore, it is noteworthy that the $3 \mathrm{D}$ printed sensor has a low production cost and did not require laborious surface modification steps with metallic or carbon-based nanomaterials. The proposed BIA-AD method using 3D-printed electrodes can also be adapted for the determination of other antioxidants in biodiesel, such as tert-butylhydroquinone (TBHQ), butylhydroanisole (BHA) or butyl hydroxytoluene (BHT), which can be added to biofuels including biodiesel samples to increase oxidation stability. The electrochemistry of TBHQ on a graphenePLA composite has been demonstrated recently, ${ }^{48}$ thus probably TBHQ is oxidized on the proposed 3D-printed $\mathrm{CB} / \mathrm{PLA}$ and hence its electrochemical profile needs to be evaluated. Eventually, the electrochemical oxidation of two antioxidants (e.g., TBHQ and PY) can be accomplished using multiple-pulse amperometric detection. Further investigation is required depending on the analyzed samples (biodiesel or other biofuels) and antioxidants added by the biofuel producers. Nevertheless, the proposed BIA-AD method can be easily adapted for the quality control of biofuels.

\section{Conclusions}

This work has showed that the environmentally-friendly composite made of carbon black-integrated PLA can be used to fabricate 3D-printed electrodes to be applied for the quality control of biodiesel using the portable BIA system. The CB/PLA electrode was successfully used as a working electrode for the determination of PY by BIA-AD in soybean biodiesel samples as well as in a commercial biodiesel sample. The proposed protocol is precise, accurate and sensitive, which are confirmed by the repeatability and recovery studies. Selectivity of the sensor was also confirmed through assessments with interfering agents. Therefore, it is possible to conclude that the use of such a source of disposable electrodes for this purpose makes the method cheaper and portable, allowing field analysis. It is noteworthy that the CB/PLA electrode presented an analytical performance comparable to conventional electrodes for the determination of antioxidant PY. Thus, the proposed 3D-printed electrode has proven to be an 
important analytical tool for applications in biofuels as well in other types of samples.

\section{Supplementary Information}

Supplementary data (voltammetric data regarding $\mathrm{pH}$ variation of the supporting electrolyte and amperometric data regarding optimization of the analytical parameters for the determination of pyrogallol) are available free of charge at http://jbcs.sbq.org.br as PDF file.

\section{Acknowledgments}

The authors are grateful to the Brazilian agencies CAPES (001), CNPq (427731/2018-6, 307271/2017-0, and 163330/2020-4), FAPEMIG (PPM-00640-16) and INCTBio (CNPq grant No. 465389/2014).

\section{References}

1. Ngo, T. D.; Kashani, A.; Imbalzano, G.; Nguyen, K. T. Q.; Hui, D.; Composites, Part B 2018, 143, 172.

2. Dragone, V.; Sans, V.; Rosnes, M. H.; Kitson, P. J.; Cronin, L.; Beilstein J. Org. Chem. 2013, 9, 951.

3. Wang, L.; Pumera, M.; TrAC, Trends Anal. Chem. 2021, 135, 116151.

4. Agrawaal, H.; Thompson, J. E.; Talanta Open 2021, 3, 100036.

5. Carrasco-Correa, E. J.; Simó-Alfonso, E. F.; Herrero-Martínez, J. M.; Miró, M.; TrAC, Trends Anal. Chem. 2021, 136, 116177.

6. Martín de Vidales, M. J.; Nieto-Márquez, A.; Morcuende, D.; Atanes, E.; Blaya, F.; Soriano, E.; Fernández-Martínez, F.; Catal. Today 2019, 328, 157.

7. Cardoso, R. M.; Kalinke, C.; Rocha, R. G.; dos Santos, P. L.; Rocha, D. P.; Oliveira, P. R.; Janegitz, B. C.; Bonacin, J. A.; Richter, E. M.; Munoz, R. A. A.; Anal. Chim. Acta 2020, 1118, 73

8. Pang, Y.; Cao, Y.; Chu, Y.; Liu, M.; Snyder, K.; MacKenzie, D.; Cao, C.; Adv. Funct. Mater. 2020, 30, 1906244.

9. Browne, M. P.; Redondo, E.; Pumera, M.; Chem. Rev. 2020 , 120,2783

10. Silva, A. L.; Salvador, G. M. S.; Castro, S. V. F.; Carvalho, N. M. F.; Munoz, R. A. A.; Front. Chem. 2021, 9, 684256.

11. Omar, M. H.; Razak, K. A.; Ab Wahab, M. N.; Hamzah, H. H.; RSC Adv. 2021, 11, 16557.

12. Manzanares Palenzuela, C. L.; Novotný, F.; Krupička, P.; Sofer, Z.; Pumera, M.; Anal. Chem. 2018, 90, 5753.

13. Vaněčková, E.; Bouša, M.; Nováková Lachmanová, Š.; Rathouský, J.; Gál, M.; Sebechlebská, T.; Kolivoška, V.; J. Electroanal. Chem. 2020, 857, 113745 .

14. Jain, S. K.; Tadesse, Y.; Int. J. Nanosci. 2019, 18, 1850026.

15. Sfragano, P. S.; Laschi, S.; Palchetti, I.; Front. Chem. 2020, 8 , 644
16. Cardoso, R. M.; Mendonça, D. M. H.; Silva, W. P.; Silva, M. N. T.; Nossol, E.; da Silva, R. A. B.; Richter, E. M.; Muñoz, R. A. A.; Anal. Chim. Acta 2018, 1033, 49.

17. Richter, E. M.; Rocha, D. P.; Cardoso, R. M.; Keefe, E. M.; Foster, C. W.; Munoz, R. A. A.; Banks, C. E.; Anal. Chem. 2019, $91,12844$.

18. Rocha, D. P.; Rocha, R. G.; Castro, S. V. F.; Trindade, M. A. G.; Munoz, R. A. A.; Richter, E. M.; Angnes, L.; Electrochem. Sci. $A d v$., in press, DOI: 10.1002/elsa.202100136.

19. Rocha, D. P.; Squissato, A. L.; da Silva, S. M.; Richter, E. M.; Munoz, R. A. A.; Electrochim. Acta 2020, 335, 135688.

20. Tully, J. J.; Meloni, G. N.; Anal. Chem. 2020, 92, 14853.

21. Cardoso, R. M.; Castro, S. V. F.; Stefano, J. S.; Muñoz, R. A. A.; J. Braz. Chem. Soc. 2020, 31, 1764.

22. Cardoso, R. M.; Rocha, D. P.; Rocha, R. G.; Stefano, J. S.; Silva, R. A. B.; Richter, E. M.; Muñoz, R. A. A.; Anal. Chim. Acta 2020, 1132, 10.

23. de Oliveira, F. M.; de Melo, E. I.; da Silva, R. A. B.; Sens. Actuators, B 2020, 321, 128528.

24. Veloso, W. B.; Ribeiro, G. A. C.; da Rocha, C. Q.; Tanaka, A. A.; da Silva, I. S.; Dantas, L. M. F.; Measurement 2020, 155, 107516.

25. Ribeiro, G. A. C.; da Rocha, C. Q.; Veloso, W. B.; Fernandes, R. N.; da Silva, I. S.; Tanaka, A. A.; Microchem. J. 2019, 146, 1249.

26. Corrêa Ribeiro, G. A.; Quintino da Rocha, C.; Tanaka, A. A.; Santos da Silva, I.; Anal. Methods 2018, 10, 2034.

27. Higino, G. S.; Machado, Í. R.; Nascimento, G. F.; Pedrotti, J. J.; J. Braz. Chem. Soc. 2021, 32, 2215.

28. OriginPro, 8.5; OriginLab Corp., Northampton, USA, 2010.

29. Serqueira, D. S.; Fernandes, D. M.; Cunha, R. R.; Squissato, A. L.; Santos, D. Q.; Richter, E. M.; Munoz, R. A. A.; Fuel 2014, $118,16$.

30. Ataide, V. N.; Rocha, D. P.; de Siervo, A.; Paixão, T. R. L. C.; Muñoz, R. A. A.; Angnes, L.; Microchim. Acta 2021, 188, 388.

31. Hung, C. H.; Chang, W. T.; Su, W. Y.; Cheng, S. H.; Electroanalysis 2014, 26, 2237.

32. Nasr, B.; Hsen, T.; Abdellatif, G.; J. Environ. Manage. 2009, 90, 523.

33. Cañizares, P.; Lobato, J.; Paz, R.; Rodrigo, M. A.; Sáez, C.; Water Res. 2005, 39, 2687.

34. Mocak, J.; Bond, A. M.; Mitchell, S.; Scollary, G.; Bond, A. M.; Pure Appl. Chem. 1997, 69, 297.

35. Knothe, G.; Steidley, K. R.; Fuel Process. Technol. 2018, 177, 75.

36. Fernandes, D. M.; Squissato, A. L.; Lima, A. F.; Richter, E. M.; Munoz, R. A. A.; Renewable Energy 2019, 139, 1263.

37. Agência Nacional do Petróleo, Gás Natural e Biocombustíveis (ANP); Resolução No. 842, de 14 de maio de 2021, Estabelece a Especificação do Diesel Verde, bem como as Obrigações Quanto ao Controle da Qualidade a Serem Atendidas Pelos 
Agentes Econômicos que o Comercializem em Território Nacional; ANP: Rio de Janeiro, 2021, available at https://www. in.gov.br/en/web/dou/-/resolucao-anp-n-842-de-14-de-maiode-2021-320059616, accessed in January 2022.

38. Rocha Jr., J. G.; dos Santos, M. D. R.; Madeira, F. B.; Rocha, S. F. L. S.; Bauerfeldt, G. F.; da Silva, W. L. G.; Salomão, A. A.; Tubino, M.; J. Braz. Chem. Soc. 2019, 30, 1751.

39. de Santana, P. M. B.; Meira, M.; Tentardini, E. K.; Mater. Res. 2015, 18, 164.

40. Domingos, A. K.; Saad, E. B.; Vechiatto, W. W. D.; Wilhelm, H. M.; Ramos, L. P.; J. Braz. Chem. Soc. 2007, 18, 416.

41. Ryu, K.; J. Mech. Sci. Technol. 2009, 23, 3105.

42. Instituto Nacional de Metrologia, Normalização e Qualidade Industrial (INMETRO); DOQ-CGCRE-008, Orientações sobre Validação de Métodos Analíticos, 2020, available at http://www. inmetro.gov.br/Sidoq/Arquivos/Cgcre/DOQ/DOQ-Cgcre-8_05. pdf, accessed in January 2022.
43. Cardoso, R. M.; Dornellas, R. M.; Lima, A. P.; Montes, R. H. O.; Richter, E. M.; Munoz, R. A. A.; J. Braz. Chem. Soc. 2017, 28,1650 .

44. Araujo, A. S. A.; Caramit, R. P.; Oliveira, L. C. S.; Ferreira, V. S.; Electroanalysis 2015, 27, 1152.

45. Chýlková, J.; Tomášková, M.; Janíková, L.; Šelešovská, R.; Navrátil, T.; Chudobová, P.; Chem. Pap. 2017, 71, 1047.

46. Ziyatdinova, G.; Gainetdinova, A.; Morozov, M.; Budnikov, H.; Grazhulene, S.; Red'kin, A.; J. Solid State Electrochem. 2012, 16, 127.

47. Matemadombo, F.; Apetrei, C.; Nyokong, T.; RodríguezMéndez, M. L.; de Saja, J. A.; Sens. Actuators, B 2012, 166-167, 457.

48. Joao, A. F.; Matias, T. A.; Gomes, J. S.; Guimaraes, R. R.; Sousa, R. M. F.; Munoz, R. A. A.; ACS Sustainable Chem. Eng. 2021, 9, 16052 . 